\title{
Glycemic control and glucose fluctuations in pregnancy and the progression of retinopathy in type I diabetes mellitus: retrospective study
}

\begin{abstract}
Aim: Rapid lowering of blood glucose has been suggested to accelerate the progression of retinopathy in pregnant diabetic women. We examined the relationship between the degree of glycemic control or the fluctuations in blood glucose and the course of retinopathy in pregnant women with type 1 diabetes mellitus.
\end{abstract}

Methods: Retrospective analysis of glycemic parameters and severity of retinopathy of 49 sets of two trimesters in 38 women with type 1 diabetes mellitus documented with seven standard field stereo fundus photographs.

Results: Retinopathy progressed in 18(36.7\%) sets of two trimesters. Age, duration of diabetes, White classification, hypertension and gravidity were not significantly correlated with changes in severity of retinopathy. Base-line HbAlc was significantly higher in the progression group $(\mathrm{P}=0.003)$. The magnitude of the decreased in $\mathrm{HbAc1}$ from base line was greater in the progression group $(\mathrm{P}=0.04)$. Logistic regression model was used to determine the influence of several risk factors in describing the change in severity of retinopathy between visits. Base line higher $\mathrm{HbAlc}$ was the only significant variable in describing progression $(\mathrm{P}=0.01)$. Base line higher $\mathrm{HbAlc}$ was associated significantly with the development of soft exudates $(\mathrm{P}=0.02)$ and soft exudate/IRMA $(\mathrm{P}=0.01)$. No statistically difference was found between base line means, standard deviation of the means of the blood glucose levels of each five measurements during the day or the standard deviation of all of the blood glucose levels in the groups and individual lesions analysis.

Conclusion: Poor glycemic control early in pregnancy and the magnitude of improvement in glycemic control rather than the fluctuations in the blood glucose levels may be critical in the progression in diabetic retinopathy.

Keywords: type 1 diabetes mellitus, retinopathy, proliferative diabetic retinopathy
Volume 6 Issue I - 2018

\author{
Khalid S Aljabri,' lain Begg,'2 David M \\ Thompson $^{3}$ \\ 'Department of Endocrinology, King Fahad Armed Forces \\ Hospital, Saudi Arabia \\ ${ }^{2}$ Department of Ophthalmology, University of British of \\ Columbia, Canada \\ ${ }^{3}$ Division of Adult Endocrinology and Metabolism, Department \\ of Medicine, University of British, Canada
}

Correspondence: Khalid S Aljabri, Department of Endocrinology, King Fahad Armed Forces Hospital, Jeddah, Kingdom of Saudi Arabia, PO Box 9862, Jeddah 21 I59, Kingdom of Saudi Arabia, Tel +966590008035, Fax +96625760665, Email khalidsaljabri@yahoo.com

Received: October 23, 2017 | Published: February 21, 2018
Abbreviations: ETDRS, early treatment diabetes retinopathy scale; SES, soft exudates; PDR, proliferative diabetic retinopathy

\section{Introduction}

Although evidences have shown that long term near normal glycemic control delays the progression of microvascular complications in type 1 diabetes including retinopathy, ${ }^{1-3}$ rapid near normalization of glycemic control has been suggested to accelerate the progression of retinopathy in nonpregnant $t^{4-8}$ and pregnant ${ }^{9-12}$ diabetic patients. Progression of diabetic retinopathy during pregnancy could occur in $14-85 \%$ of cases, ${ }^{9,11-22}$ others found no association. ${ }^{23-25}$ Study on normal cat found that the retinovascular response to glucose infusion suggests a breakdown in the normal response of tissue autoregulation. ${ }^{26}$ Although elevated blood glucose levels are associated with decreased retinal arterial regulatory responses which could play a role in the development of diabetic retinopathy, ${ }^{27,28}$ gradual decrease in blood glucose may be beneficial. ${ }^{29}$ Short term fluctuations in plasma glucose levels were not associated with hemodynamic changes in the macular capillaries in patients with established retinopathy. ${ }^{30}$ To clarify this issue and explore the etiology of transient worsening of retinopathy, we addressed: i. Does the degree of glycemic control affect the course of retinopathy in pregnant women with type 1 diabetes;

ii. Do blood glucose fluctuations affect the course of retinopathy.

\section{Patients and methods}

We conducted a retrospective analysis of 49 sets of two trimesters in 38women who completed 41 pregnancies under strict blood glucose control with type 1diabetes who were followed in the diabetes clinic at the British Columbia Women's Hospital and the University of British Columbia Ocular Diabetes Clinic. All eligible women, defined as having a diagnosis of type 1 diabetes using standard clinical criteria $^{31}$ and at least two visits to both clinics during the pregnancy are included in this report. Data were obtained from chart review and contact with women and their physician. The ethical review board of the University of British Columbia approved the study. Complete medical and obstetric histories were documented in the chart. Pregnancy dating was based on menstrual dates and confirmed by ultrasonographic examination. Glycemic control was maintained with regimens of short- and intermediate-acting insulin preparations injected two to four times per day and insulin adjustment along 
with dietary regulation was made daily by a team of diabetes nurse clinicians and physicians. The diabetes clinic asked women to monitor blood glucose at least four times a day and aimed for glucose levels of $4-6 \mathrm{mmol} / 1$ before meals. Blood glucose levels of pre-meals including breakfast, lunch, supper, bedtime, and 2 am were measured. HbA1c values were measured in clinical laboratories with the normal range 4.3-6.2, value expressed as time the power of 10-2. White classes for diabetes in pregnancy are defined as B: onset after age 20 and duration less than 10years, C: onset between ages 10 and 19 or duration of 10-19years, D: onset before age 10 or duration more than 20years or hypertension, R: proliferative retinopathy, F: nephropathy, RF: both proliferative retinopathy and nephropathy. Hypertension before pregnancy was diagnosed if the blood pressure raised more than $140 / 90$ or on anti-hypertensive medications. Current age was defined as the age in years as reported at the first visit. Duration of diabetes was the period between the reported age at diagnosis of diabetes and the age at the first visit.

\section{Retinopathy assessment}

Seven standard fields stereoscopic color fundus photographs were available for comparison for the two trimesters and graded (with grader blinded to the clinical data) according to the Early Treatment Diabetes Retinopathy Scale (ETDRS) modifications of the Airlie House classification which provides a grade for the severity of each type of lesion of diabetic retinopathy for each eye. Grades for the various lesions were used to derive overall retinopathy severity levels for each woman according to the ETDRS interim and final scale. ${ }^{32,33}$ Retinopathy outcomes were divided into two groups; progression and non-progression as compared with base line retinal assessment. Retinopathy progression was defined as a higher grade of retinopathy on the final ETDRS by at least one Step. ${ }^{34}$ The development of soft exudates (SEs), intraretinal microvascular abnormalities (IRMAs), and soft exudate/intraretinal microvascular abnormality were analyzed separately. ${ }^{35-37}$

\section{Statistic analysis}

The unit of analysis in this paper is a set of two trimesters. Mean, standard deviation and $95 \%$ confidence intervals of the mean, the standard deviation of each five measurements of blood glucose levels during the day were measured for analysis. Data were analyzed with SPSS V 22.0 .Unpaired t-test student used for parametric and Mann-Whitney test for nonparametric data, chi square and Fisher's exact used for categorical data. Logistic regression model was used to determine the influence of several risk factors in describing the change in severity of retinopathy between visits. $\mathrm{P}<0.05$ is significant.

\section{Results}

Of 300 hospital charts reviewed, 38 type 1 diabetic women were pregnant with 41 completed pregnancies and 49 sets of two trimesters in which seven standard field colour fundus photographs had been taken fulfilled the inclusion criteria were eligible for analysis. A woman ranged in age from 19 to 39 years (mean \pm standard deviation, $28.7 \pm 4.5$ ). The duration of diabetes was 3 to 31 years. The body mass index was 19.4 to $35.5 \mathrm{~kg} / \mathrm{m}$ (mean \pm standard deviation, $24.4 \pm 3.4$ ). As shown in Table 1, progression group has longer diabetes duration $(\mathrm{P}=0.2)$. White class $\mathrm{B}$ was found in $22.6 \%$ of the nonprogression group (Odd ratio=5.0 $(0.6-44.1), \mathrm{P}=0.2$ ), where as Class $\mathrm{C}$ (Odd ratio=1.6 (0.4-6.3), $\mathrm{P}=0.5)$ and $\mathrm{D}-\mathrm{ER}-\mathrm{F}$ (Odd ratio=1.4 (0.4-4.9), $\mathrm{P}=0.6)$ were associated nonsignificantly with progression. Because these cases were compared in different trimesters of pregnancy, we found, although the numbers are small, there was 3.8-fold (1.1-13.1, $\mathrm{P}=0.03$ ) significant association with retinopathy not to be progressed if the baseline retinal assessment were at the second trimester which may not suggest a possible peak during the second trimester as it was suggested. ${ }^{22}$ There was 2.9 -fold (0.8-9.8) nonsignificant increase risk of progression in the first trimester ( $50 \%$ vs. $25.8 \%, \mathrm{P}=0.09)$. Age, BMI, chronic hypertension, pregnancy induced hypertension, gravidity, and gestational age were not significantly associated with changes of retinopathy between visits.

Table I Characteristics of retinopathy outcomes at baseline

\begin{tabular}{llll}
\hline Parameters & \multicolumn{2}{l}{ Retinopathy outcomes } & P value \\
\hline \multicolumn{1}{l}{ Progression } & Non-progression \\
\hline Total & $18(36.7)$ & $31(63.3)$ & \\
Age (years) & $29.1 \pm 4.4$ & $28.5 \pm 4.7$ & 0.6 \\
Body mass index (kg/m) & $23.9 \pm 3.8$ & $24.7 \pm 3.2$ & 0.4 \\
Diabetes duration (years) & $17(13.8,25)$ & $15.5(9.5,21)$ & 0.2 \\
White Classification & & & \\
B & $1(5.6)$ & $7(22.6)$ & 0.2 \\
C & $5(27.8)$ & $6(19.4)$ & 0.5 \\
D-RF & $12(66.7)$ & $18(58.1)$ & 0.6 \\
Chronic hypertension & $2(11.1)$ & $1(3.2)$ & 0.5 \\
Pregnancy induced hypertension & $8(44.4)$ & $7(22.6)$ & 0.1 \\
Primigravida & $8(44.4)$ & $10(32.3)$ & 0.5 \\
Gestational age (days) & $259.3 \pm 8$ & $255.2 \pm 8.9$ & 0.1 \\
Birth weight (kg) & $3.8 \pm 0.6$ & $3.6 \pm 0.7$ & 0.2 \\
\hline
\end{tabular}


Table Continued..

\begin{tabular}{|c|c|c|c|}
\hline \multirow[t]{2}{*}{ Parameters } & \multicolumn{2}{|c|}{ Retinopathy outcomes } & \multirow[t]{2}{*}{$P$ value } \\
\hline & Progression & Non-pr & \\
\hline \multicolumn{4}{|l|}{ Time point of trimesters } \\
\hline $1^{\text {st }}$ trimester- $2^{\text {nd }}$ trimester & $9(50)$ & $8(25.8)$ & 0.09 \\
\hline $2^{\text {nd }}$ trimester- $3^{\text {rd }}$ trimester & $7(38.9)$ & $22(7 I)$ & 0.03 \\
\hline$\left.\right|^{\text {st }}$ trimester- $3^{\text {rd }}$ trimester & $2(I I . I)$ & $\mathrm{I}(3.2)$ & 0.5 \\
\hline \multicolumn{4}{|l|}{ Retinopathy } \\
\hline No retinopathy & $\mathrm{I}(5.6)$ & $\mathrm{I}(3.2)$ & 0.7 \\
\hline Microaneurysm or hemorrhage & $7(38.9)$ & $8(25.8)$ & 0.3 \\
\hline \multicolumn{4}{|l|}{ without microaneurysm } \\
\hline Mild nonproliferative diabetic retinopathy & $3(16.7)$ & $9(29)$ & 0.5 \\
\hline $\begin{array}{l}\text { Moderate nonproliferative diabetic } \\
\text { retinopathy }\end{array}$ & $7(38.9)$ & $3(9.7)$ & 0.03 \\
\hline $\begin{array}{l}\text { Moderately severe nonproliferative } \\
\text { diabetic retinopathy }\end{array}$ & 0 & $2(6.5)$ & 0.5 \\
\hline Proliferative diabetic retinopathy & 0 & $8(25.8)$ & 0.1 \\
\hline
\end{tabular}

Data are number $(\%)$, mean $(\mathrm{SD})$, or median $\left(25^{\text {th }}\right.$ centile, $75^{\text {th }}$ centile)

Retinopathy status as listed in Table 1, 18 (36.7\%) compared trimesters were progressed, 31(63.3\%) showed no progression from baseline. At baseline, no retinopathy was found in 2 sets of trimesters $(\mathrm{P}=0.7)$. Microaneurysm or hemorrhage without microaneurysm were progressed in $38.9 \%$ (Odd ratio=1.8(0.5-6.3), $\mathrm{P}=0.3$ ). Mild nonproliferative diabetic retinopathy was found in $16.7 \%$ in the progression group (Odd ratio $=0.5(0.1-2.1), \mathrm{P}=0.5)$. Moderate nonproliferative diabetic retinopathy was present in $38.9 \%$ in the progression group, $9.7 \%$ in the nonprogression group (Odd ratio $=5.9$ (1.3-27.2), $\mathrm{P}=0.025)$. At baseline, the non-progression group showed moderately severe nonproliferative diabetic retinopathy $(\mathrm{P}=0.5)$ and proliferative diabetic retinopathy $(\mathrm{PDR})(\mathrm{P}=0.1)$ in $6.5 \%$ and $25.8 \%$ of the sets of trimesters respectively. $55.6 \%$ were progressed by one step. Soft exudates were developed in $22.4 \%$, where microaneurysm or hemorrhage without micro-aneurysm significantly found at base line (odds ratio $=5.5(1.2-25), \mathrm{P}=0.03$ ). The presence of IRMA in $16.3 \%$ which was significantly associated with presence of moderate NPDR at baseline (odds ratio=32.5(4.3-244.2), $\mathrm{P}=0.001$ ). No significant correlations between SEs/IRMAs with any base line retinopathy grade.

\section{Glycemic control}

A comparison of the severity of the retinopathy with the metabolic parameters is shown in Table 2. Progression group had higher baseline $\mathrm{HbA} 1 \mathrm{c}(\mathrm{P}=0.003)$. The magnitude of HbA1C decreased from base-line was higher significantly in the progression group $(\mathrm{P}=0.04)$, with significant 4.5-fold (1.0-19.1) increase in the risk of progression if the magnitude decreased in the $\mathrm{HbAlc}$ concentration by 1.5 or more
( $\mathrm{P}=0.04$, Chi square test). We looked at the severity of retinopathy between the two visits by HbAlc quartiles (Table 3 ). In the first quartile of $\mathrm{HbAlc}(<5.7)$, the sets of trimesters had a greater tendency not to progress, $\mathrm{P}=0.003$ ), while in the fourth quartile of the $\mathrm{HbA} 1 \mathrm{c}$ $(>7.7)$; the sets of trimesters had a greater tendency to progress (odds ratio=5.0 (1.2-20.5), $\mathrm{P}=0.04)$. Logistic regression model was used to determine the influence of several risk factors in describing the changes in severity of retinopathy between visits. Base line higher $\mathrm{HbAlc}$ was the only significant variable in describing progression $(\mathrm{P}=0.01)$. The mean blood glucose levels and the standard deviations of the means of the five measurements during the day were not statistically different between the two groups. The standard deviation of the absolute blood glucose values of the five measurements during the day were not statistically different (Figures 1\&2). As shown in Table 4, base line higher HbAlc was associated with the development of soft exudates $(\mathrm{P}=0.02)$ and soft exudates/IRMAs $(\mathrm{P}=0.01)$. The magnitude of decrease in $\mathrm{HbAlc}$ was associated with the development of soft exudates, with 5.8-fold (1.2-28.4) increase in the risk of development of soft exudates if the magnitude of decrease in $\mathrm{HbA} 1 \mathrm{c}$ concentration was 1.5 or more ( $\mathrm{P}=0.03$, fisher's exact test) and soft exudates/IRMA $(\mathrm{P}=0.02)$ with 4.5 -fold (1.0-19.1) increase risk of development if magnitude decreased of $\mathrm{HbAlc}$ concentration was 1.5 or more ( $\mathrm{P}=0.04$, chi square test). There were no statistically different between the base line $\mathrm{HbAlc}$, the magnitude of decrease in $\mathrm{HbAlc}$ from base line, means, standard deviation of the means of the blood glucose levels of the five measurements during the day and the standard deviation of the each five measurements of daily blood glucose levels in the analyzed individual lesions. 
Table $2 \mathrm{HbAlc}$ of retinopathy outcomes at baseline and follow up

\begin{tabular}{lllll}
\hline HbAlc & $\mathbf{I}^{\text {st }}$ quartile & $2^{\text {nd }}$ quartile & $3^{\text {rd }}$ quartile & $\mathbf{4}^{\text {th }}$ quartile \\
\hline Progression & 0 & $4(40)$ & $6(42.9)$ & $8(66.7)$ \\
Non-progression & $1 \mathrm{l}(100)$ & $6(60)$ & $8(57.1)$ & $4(33.3)$ \\
Odds ratio (95\% confidence intervals) & $1.6(1.2-2.1)$ & $1.1(0.3-4.6)$ & $1.3(0.44 .7)$ & $5(1.220 .4)$ \\
P value & 0.003 & 0.9 & 0.7 & 0.04
\end{tabular}

Data are mean \pm SD $(95 \%$ Confidence intervals)

Table 3 Retinopathy outcomes and HbAlc quartiles at baseline

\begin{tabular}{|c|c|c|c|c|}
\hline HbAlc & I st $^{\text {quartile }}$ & $2^{\text {nd }}$ quartile & $3^{\text {rd }}$ quartile & $4^{\text {th }}$ quartile \\
\hline Progression & 0 & $4(40)$ & $6(42.9)$ & $8(66.7)$ \\
\hline Non-progression & $\mathrm{II}(100)$ & $6(60)$ & $8(57.1)$ & $4(33.3)$ \\
\hline Odds ratio ( $95 \%$ confidence intervals) & $1.6(1.2-2.1)$ & I.I $(0.3-4.6)$ & I.3(0.44.7) & $5(1.220 .4)$ \\
\hline$P$ value & 0.003 & 0.9 & 0.7 & 0.04 \\
\hline
\end{tabular}

Data are $n(\%)$

Table $4 \mathrm{HbAlc}$ at baseline and follow up in relation to the development of soft exudates, IRMAs, SE and/or IRMA, and progression by steps

\begin{tabular}{|c|c|c|c|c|}
\hline Parameters & Retinopathy lesions & HbA I c at baseline & HbAlc at follow up & Decrease in HbAlc \\
\hline \multirow[t]{3}{*}{ Soft exudates } & Present & $7.3 \pm I . I(6.5-8.0)$ & $5.7 \pm 0.8(5.1-6.4)$ & $1.5 \pm 0.9(0.8-2.2)$ \\
\hline & Absent & $6.4 \pm I . I(6.0-6.8)$ & $5.8 \pm 0.9(5.5-6.1)$ & $0.7 \pm 0.8(0.4-1.0)$ \\
\hline & $P$ value & 0.023 & 0.9 & 0.013 \\
\hline \multirow[t]{3}{*}{ IRMA } & Present & $6.8 \pm 0.8(6.1-7.5)$ & $5.9 \pm 0.7(5.3-6.5)$ & $0.9 \pm 0.8(0.1-1.6)$ \\
\hline & Absent & $6.6 \pm 1.2(6.2-6.9)$ & $5.7 \pm 0.9(5.4-6.1)$ & $0.8 \pm 0.8(0.6-1.2)$ \\
\hline & $P$ value & 0.6 & 0.6 & 0.9 \\
\hline \multirow[t]{3}{*}{ SE / IRMA } & Present & $7.1 \pm 1.0(6.6-7.6)$ & $5.8 \pm 0.8(5.4-6.2)$ & $1.3 \pm 0.9(0.8-1.7)$ \\
\hline & Absent & $6.3 \pm I . I(5.8-6.7)$ & $5.7 \pm 1.0(5.4-6.1)$ & $0.6 \pm 0.8(0.3-1.0)$ \\
\hline & $P$ value & 0.01 & 0.8 & 0.024 \\
\hline \multirow[t]{3}{*}{ Progression (steps) } & I & $7.0 \pm 0.8(6.5-7.6)$ & $6.0 \pm 0.9(5.3-6.7)$ & $1.0 \pm 0.9(0.3-1.8)$ \\
\hline & $\geq 2$ & $7.4 \pm I . I(6.5-8.3)$ & $6.0 \pm 0.7(5.4-6.5)$ & $1.4 \pm 1.0(0.6-2.3)$ \\
\hline & $P$ value & 0.4 & 0.9 & 0.4 \\
\hline
\end{tabular}

Data are mean+/- SD (95\% Confidence intervals)

Citation: Aljabri KS, Begg I,Thompson DM. Glycemic control and glucose fluctuations in pregnancy and the progression of retinopathy in type I diabetes mellitus: retrospective study. Endocrinol Metab Int J. 20I8;6(I):89-95. DOI: 10.15406/emij.2018.06.00160 

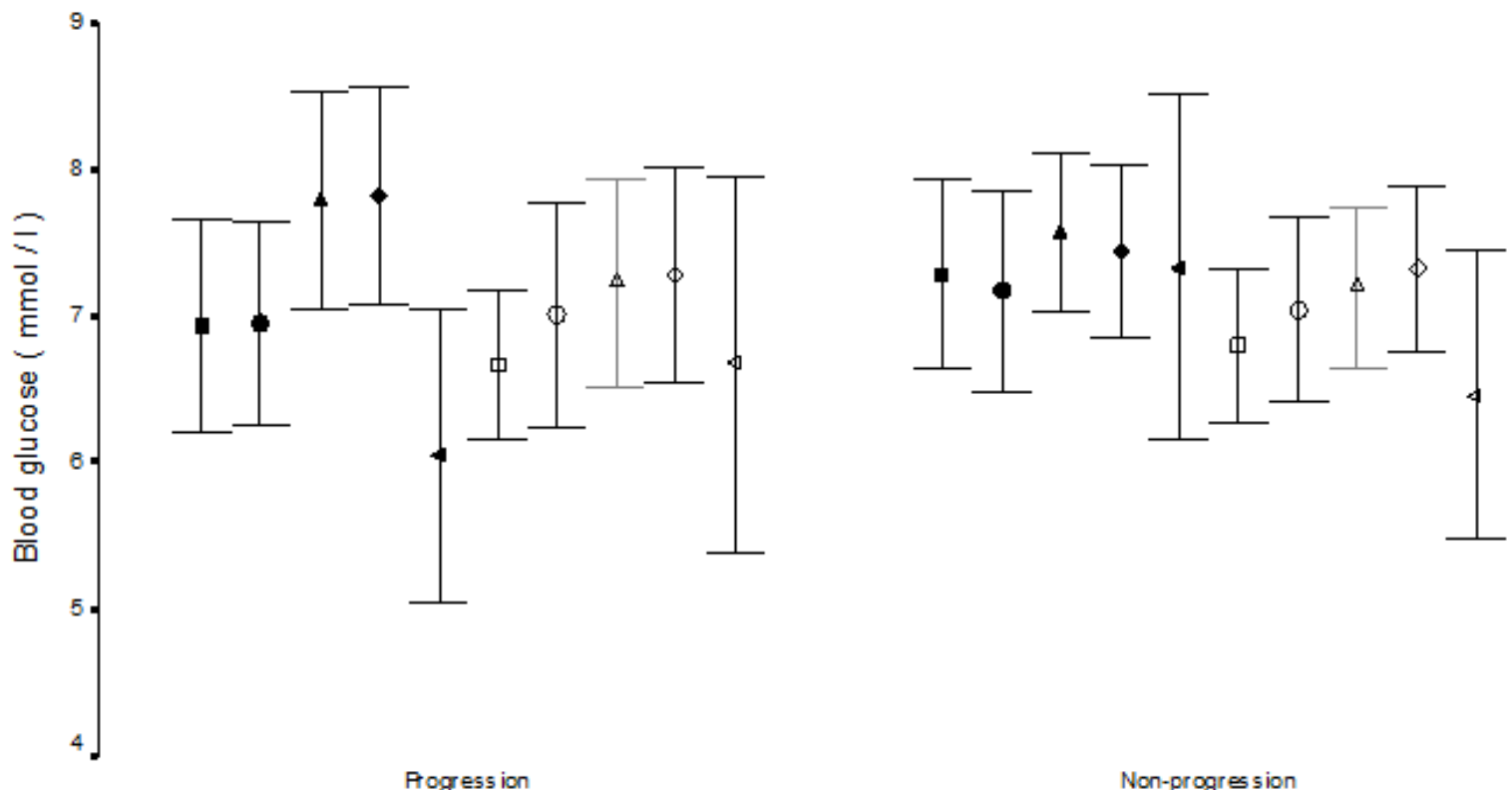

Progress ion

Non-progression

Figure I Blood glucose of each of the five measurements. Pre-meals blood glucose levels at baseline: breakfast $(\mathbf{})$, lunch $(\bullet)$, supper $(\boldsymbol{\Delta})$, bedtime $(\diamond), 2$ am $(\boldsymbol{4})$. At follow up: breakfast $(\square)$, lunch $(\circ)$, supper $(\Delta)$, bedtime $(\diamond)$, 2am $(\diamond)$. P value (each five measurements)=Not significant.
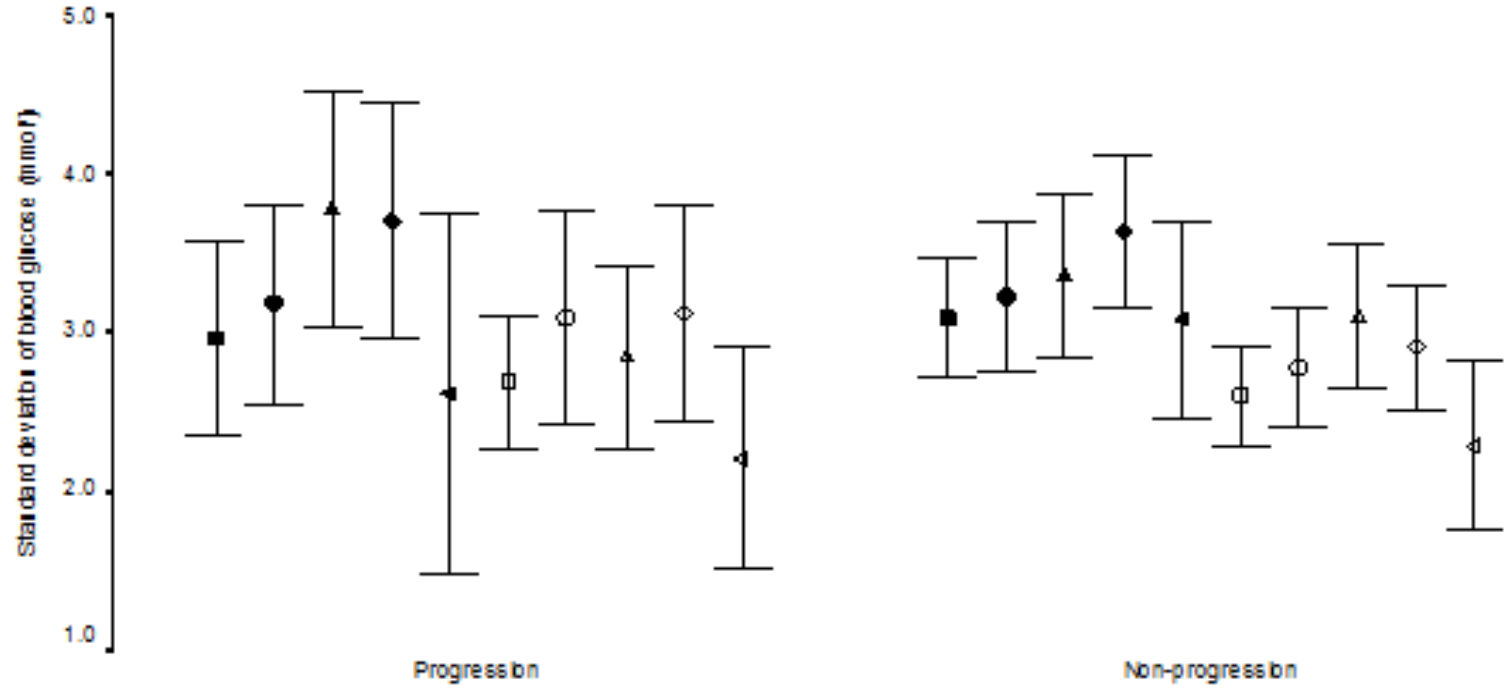

Non-progress bn

Figure 2 Standard deviations of blood glucose of each of the five measurements. Pre-meals blood glucose levels at baseline: breakfast $(\boldsymbol{\square})$, lunch $(\bullet)$, supper $(\boldsymbol{\Delta})$, bedtime $(\diamond)$, 2am $(\varangle)$. At follow up: breakfast $(\square)$, lunch $(\circ)$, supper $(\Delta)$, bedtime $(\diamond)$, 2am $(\diamond)$.. P value (each five measurements) $=$ Not significant.

\section{Discussion}

We have found retrospectively, diabetic retinopathy progressed in $36.7 \%$. Because we studied sets of two trimesters as a unit of analysis, we found a higher incidence of progression of $39 \%$ in the 41 pregnancies studied, which falls within the $14-85 \%$ incidence reported earlier, ${ }^{9,11-22}$ reflecting the value of serial ophthalmoloscopy and photography in pregnant type 1 diabetics as previously suggested..$^{15}$ Dibblie et al. ${ }^{14}$ suggested that background retinopathy may wax and wane during pregnancy. Hellstedt et al. ${ }^{35}$ reported some of the microaneurysms are occluded temporarily by fibrin or platelets thrombi and then re-canalized, which may explain some of the micro-aneurysms disappearance in our nonprogression group, however, we found that nonprogression of the retinopathy was associated not significantly with mild diabetic retinopathy at base line (odds ratio $2.0(0.5-8.8), \mathrm{P}=0.49)$ but the number of cases (9cases) are small. However, base line moderate NPDR was associated with 5.9-fold increase in the risk of progression $(\mathrm{P}=0.03)$. Understanding the risk factors that may lead to progression among diabetic women in pregnancy is of great important in the management of such cases. Therefore, we investigated the risk factors that have been proposed to influence the progression of diabetic retinopathy. Diabetes duration has been found to be correlated inversely with progression of retinopathy in non-pregnant ${ }^{38,39}$ and pregnant women. ${ }^{19,21}$ Duration of diabetes was not significantly associated with the progression group when compared to the nonprogression group $(\mathrm{P}=0.2)$ in contrast to the previous report, ${ }^{9}$ however, subgroup of the non-progression whom retinopathy were improved from baseline had shorter duration of 
diabetes (6years) when compared to progression (Odd ratio $=22.7(1.8$ 279.4), $\mathrm{P}=0.01$, fisher's exact test) which may emphasize as suggested by Soubrane et al. ${ }^{17}$ the advantage of early planning pregnancy in this population. The pathogenesis of diabetic retinopathy has been the focus in earlier studies. In such way, they could explain our findings. The rate of oxygen consumption is higher ${ }^{38}$ and the oxygen released capacity is reduced in diabetic patients, ${ }^{39}$ and the reduced oxygen consumption of the retina found in hyperglycemia may worsen the relative hypoxia. ${ }^{40}$ The increased arterial retinal blood flow found in early diabetes, ${ }^{27,41,42}$ and in hyperglycemia ${ }^{26}$ may also be reduced leading to ischemia ${ }^{10}$ after rapid normalization of blood glucose. In contrast to earlier reports, ${ }^{21,43}$ we found progression of retinopathy was related to the degree of glycemic control achieved over the course of the two trimesters studied $(\mathrm{P}=0.04)$ which was found by Phleps, Klein \& Rosenen et al. ${ }^{9,11,19}$ and the DCCT ${ }^{22}$ and in nonpregnant study ${ }^{44}$ Although we found the HbAlc was significantly higher in the progression group at baseline $(\mathrm{P}=0.003)$ as previously found in the nonpregnant $t^{44}$ and pregnant diabetic, ${ }^{12,22}$ other found association was not significant. ${ }^{21}$ The correlation between baseline HbA1c concentration and the magnitude of decrease of $\mathrm{HbAlc}$ between the two visits was $0.631(\mathrm{P}<0.01)$; higher baseline $\mathrm{HbA} 1 \mathrm{c}$ concentration were associated with greater decreases in $\mathrm{HbAlc}$ between the two visits which was consistent with Phleps et al. ${ }^{9}$ Davis et al. ${ }^{30}$ suggested that short term fluctuations in plasma glucose levels are not associated with hemodynamic changes in the macular capillaries in patients who have established retinopathy in 20 non-pregnant poorly controlled type 1 diabetic patients. A mechanism has been suggested by Grunwald et al. ${ }^{29}$ in study of poorly controlled type 2 patients (diabetes duration was $7.3 \pm 5$ years) by using laser doppler velocimetry which measures blood flow in the major retinal arteries and veins, that decrease in volume flow accompanying the insulin induced drop in blood glucose levels correlated significantly with the patient's duration of diabetes. The shorter diabetes duration, the largest decrease in flow. The duration of diabetes between the group studied by Davies et $\mathrm{al},{ }^{30}$ $(18.5 \pm 7)$ and our progression group (18.2 \pm 6.7$)$ were similar compared to the poorly controlled type 2 patients $(7.3 \pm 5)$ studied by Grunwald et al. ${ }^{27}$ may suggest patients responses to lower plasma glucose levels would be small as in Davies et al patients by using the blue light entopic technique and more difficult to be detected clinically by us. Our data provide the first detailed retrospective evidence in pregnant type 1 diabetic women that no significant correlations were found between fluctuations in the daily blood glucose levels and the changes in diabetic retinopathy. Thus, we believe our data indicate that poor glycemic control early in pregnancy and the rapidity and magnitude of improvement in glycemic control rather than the fluctuation in the blood glucose levels may be critical in the progression in diabetic retinopathy, supporting the opinion of Chew et al. ${ }^{12}$ to emphasize the importance of preconception normalization of $\mathrm{HbAlc}$ to avoid the risk of progression in pregnant women with type 1 diabetes mellitus. Soft exudates (SE) and intraretinal microvascular Abnormalities (IRMAs) are changes encountered during pregnant $t^{9,10,15,18}$ or nonpregnant patients. ${ }^{1,5,6,44}$ The soft exudates represent microinfarction in the nerve fibre layer, whereas the nature of IRMAs is controversial. ${ }^{5}$ They were often regarded as characteristic of the preproliferative phase of diabetic retinopathy, and commonly preceding the appearance of new vessels. ${ }^{1}$ SEs developed in $22.4 \%$ of the cases in our series, where as IRMAs developed in $16.3 \%$ of the cases. In agreement with DahlJorgensen et al. ${ }^{6}$ when SEs developed in the first months of treatment in his study, SEs developed during our comparison of trimester's duration
Institution of strict metabolic control associated with the development of SEs as shown by higher HbA1c concentration at baseline $(\mathrm{P}=0.02)$ and the magnitude of HbA1c change $(\mathrm{P}=0.01)$. 5,6,9,44 These significant correlations were not found for the development of IRMAs $(\mathrm{P}=0.6)$. This may be explained by the relative good glycemic control at baseline and the drop in $\mathrm{HbA} 1 \mathrm{c}$ concentration were not high. However, the higher HbAlc concentration at baseline $(\mathrm{P}=0.01)$ and decreased in the HbA1c concentration from baseline $(\mathrm{P}=0.02)$ may contribute in development of SEs/IRMAs. ${ }^{44}$ In contrast to the DCCT, ${ }^{22,44}$ as evidence by our data, steps progression were not significant correlated with the higher $\mathrm{HbA} 1 \mathrm{c}$ concentration at baseline $(\mathrm{P}=0.43)$ and decreased in $\mathrm{HbAlc}$ concentration from baseline $(\mathrm{P}=0.4)$, that could be attributed to both groups start with similar $\mathrm{HbAlc}$ concentration and the magnitude of $\mathrm{HbAlc}$ change between the different in steps were identical and the sample size were small to show a significant difference. As the case earlier, the Plasma glucose fluctuation in the daily blood glucose levels was not correlated. To conclude; we believe our data indicate that poor glycemic control early in pregnancy and the rapidity and magnitude of improvement in glycemic control rather than the fluctuations in the blood glucose levels may be critical in the progression in diabetic retinopathy.

\section{Acknowledgments}

We are grateful to all who assisted in this study at the British Bolumbia women and children hospital, Vancouver, British Columbia Canada. No grants were assigned to this study.

\section{Conflicts of interest}

Authors have no conflicts of interests.

\section{Funding}

None.

\section{References}

1. The Kroc collaborative study group Diabetic retinopathy after two years of intensified insulin therapy. JAMA. 1988;260(1):37-41.

2. The DCCT The effect of intensive treatment of diabetes on the development and progression of long-term complications in insulin dependent diabetes mellitus. N Engl J Med. 1993;329(14):977-186.

3. The DCCT The effect of intensive diabetes treatment of on the progression of diabetic retinopathy in insulin dependent diabetes mellitus. Arch Of Ophthalmol. 1955;113(1):36-51.

4. Van Ballegooie E, Hooymans JM, Timmerman Z, et al. Rapid deterioration of diabetic retinopathy during treatment with continuous subcutaneous insulin infusion. Diabetes Care. 1884;7(3):236-242.

5. The Kroc Collaborative study group Blood glucose control and the evolution of diabetic retinopathy and albuminoidal. $N$ Engl $\mathrm{J} \mathrm{Med}$. 1984;311(6):365-372.

6. Dahl-Jorgensen K, Brinchmann-Hansen O, Hanssen K, et al. Rapid tightening of blood glucose control leads to transient deterioration of retinopathy in insulin dependent diabetes mellitus: the Oslo study. $\mathrm{Br} \mathrm{Med}$ J. 1985;290(6471):811-815.

7. Brincmann-Hansen O, Dahl-Jorgensen K, Hansen K, et al. the Oslo study group. Effects of intensified insulin treatment on various lesion of diabetic retinopathy. American Journal of Ophthalmology.1985;100(5):644-653.

8. Pandona $\mathrm{P}$, Bolger J, Boag F, et al. Rapid development and progression of proliferate retinopathy after strict diabetic control. $\mathrm{Br} \mathrm{Med} J$. 1996;290(6472):895-896 
9. Phleps R, Sakol P, Metzger B, et al. Changes in diabetic retinopathy during pregnancy. Archive of Ophthalmol. 1986;104:1806-1810.

10. Laatikainen L, Teramo K, Heita-Heikurainen H, et al. A controlled study of influence of continuous subcutaneous insulin infusion treatment on diabetic retinopathy during pregnancy. Act Med Scand. 1987;221(4):367376.

11. Klein B, Moss S, Klein R. Effect of pregnancy on progression of diabetic retinopathy. Diabetes Care. 1990;13(1):34-4012.

12. Chew E, Mills J, Metzger B, et al. Metabolic control and progression of retinopathy. Diabetes Care. 1995;18(5):631-637.

13. Johnston G. Pregnancy and diabetic retinopathy. Am J of Ophthalmol. 1980;90(4):519-524.

14. Dibble C, Kochenour N, Worley R, et al. Effect of pregnancy on diabetic retinopathy. Obstet Gynecol. 1982;59(6):699-704.

15. Moloney J, Drury M. The effect of pregnancy on the natural course of diabetic retinopathy. Am J of Ophthalmol 1982;93(6):745-756.

16. Ohrot V. The influence of pregnancy on diabetic retinopathy with special regard to the reversible changes shown in 100 pregnancies. Acta Ophthalmol. 1984;62(4):603-616.

17. Soubrane G, Canivet J, Coscas G. Influence of pregnancy on the evolution of background retinopathy. Intern Ophthalmol. 1985;8(4):249-255.

18. Serup L. Influence of pregnancy on diabetic retinopathy. Acta Endocrinol Suppl (Copenh). 1986;277:122-124.

19. Rosenn B, Miodovnik M, Kranias G, et al. Progression of diabetic retinopathy on pregnancy: association with hypertension in pregnancy . Am J Obstet Gynecol. 1992;166(4):1214-1218.

20. Hemachandra A, Lloyd C, Ellis D, et al. The influence of pregnancy on IDDM complications. Diabetes Care. 1995;18(7):950-954.

21. Axer-Siegel R, Hod M, Fink-cohen S, et al. Diabetic retinopathy during pregnancy. Ophthalmol. 1996;103(11):1815-1919.

22. The DCCT Effect of pregnancy on micro vascular complications in the diabetes control and complications trial. Diabetes Care. 2000;23(8):1084 1091.

23. Horvat M, Maclean H, Goldberg L, et al. Diabetic retinopathy in pregnancy: a 12-years prospective survey. Br J Ophthalmol. 1980;64(6):398-403.

24. Christensen L, Frost-Laren K, Fugleberg S, et al. Does pregnancy influences the prognosis of uncomplicated insulin dependent diabetes mellitus. Diabetes Care. 1982;5:1-5.

25. Lapolla A, Cardone C, Negrin P, et al. Pregnancy does not induce or worsen retinal and peripheral nerve dysfunction in insulin dependent diabetic women. J Diabet Complicat. 1998;12(2):74-80

26. Atherton A, Hill D, Keen H, et al. The effect of acute hyperglycemia on the retinal circulation of the normal cat. Diabetologia. 1980;18(3):233-237.

27. Grunwald J, DuPont J, Riva C. Retinal homodynamic in patients with early diabetes mellitus. Br J Ophthalmol.1996;80(4):327-331.
28. Sinclair S, Grunwald J, Riva C, et al. Retinal vascular auto regulation in diabetes mellitus. Ophthalmol. 1982;89(7):748-750.

29. Grunwald J, Riva C, Martin M, et al. Effect of insulin induced decrease in blood glucose on the human diabetic retinal circulation. Ophthalmol. 1987;94(12):1614-1620.

30. Davies E, Hyer S, Kohner E. Macular blood flow response to acute reduction of plasma glucose in diabetic patients measured by the blue light entoptic technique. Ophthalmology. 1990;97(2):160-164.

31. Report of the expert committee on the diagnosis and classification of diabetes mellitus. Diabetes Care. 40(Suppl 1):S11-S24.

32. Early Treatment Diabetic Retinopathy Study Research Group. Grading diabetic retinopathy from stereoscopic color fundus photographs: an extension of the modified Airlie House Classification: ETDRS report No.10. Ophthalmol. 1991;98(5 Suppl):786-806.

33. Early Treatment Diabetic Retinopathy Study Research Group. Fundus photographic risk factors for progression of diabetic retinopathy: ETDRS report No.12. Ophthalmol. 1991;98(5 Suppl):823-833.

34. Klein R, Klein B, Scott E, Moss M. How many steps are of progression of diabetic retinopathy are meaningful? The Wisconsin Epidemiologic Study of Diabetic Retinopathy. Arch Ophthalmol. 2001;119(4):547-553.

35. Helstedt T, Immonem I. Disappearance and formation rates of microaneurysms in early diabetic retinopathy. $\mathrm{Br} J$ Ophthalmol. 1996;80(2):135-139.

36. Klein R, Klein BE, Moss SE, et al. The Wisconsin epidemiologic study of diabetic retinopathy. Arch Ophthalmol. 1984;102(4):520-526.

37. Klein R, Klein BE, Moss SE, et al. The Wisconsin epidemiologic study of diabetic retinopathy. Arch Ophthalmol. 1984;102(4):527-532.

38. Hortsman P. The oxygen consumption in diabetes mellitus. Acta medical scand. $1951 ; 139(4): 326$.

39. Ditzel J. Impaired oxygen release caused by alterations of the metabolism in erythrocytes in diabetes. Lancet. 1972;299(1):721-723.

40. Hickam J, Frayser R. Studies of the retinal circulation in man. Observations on vessel diameter, arteriovenous oxygen differences, and mean circulation time. Circulation. 1966;33(2):302.

41. Kohner E, Hamilton A, Saunders J, et al. The retinal blood flow in diabetes. Diabetologica. 1975;11(1):27-33.

42. Yoshida A, Feke G, Morales-Stopello J, et al. Retinal blood flow alterations during progression of diabetic retinopathy. Arch Ophthalmol. $1983 ; 101(2): 225$

43. Chang S, Fuhrmann M, Jovanovic L. The Diabetes in early pregnancy study Group (DIEP): pregnancy, retinopathy, normoglycemia: a preliminary analysis. Diabetes. 1985;35(Suppl):3A.

44. The DCCT. Early worsening of Diabetic retinopathy in the diabetes control and complications trial. Arch Ophthalmol. 1998;116(7):874-886. 